\begin{tabular}{|c|c|}
\hline Title & Low prevalence of juvenile-onset Behçet's disease with uveitis in East/South A sian people \\
\hline Author(s) & Kitaichi, Nobuyoshi; Miyazaki, A kiko; Stanford, Miles R.; Iwata, Daiju; Chams, Hormoz; Ohno, Shigeaki \\
\hline Citation & $\begin{array}{l}\text { British Journal of Ophthalmology, 93(11), 1428-1430 } \\
\text { https://doi.org/10.1136/0jo.2008.154476 }\end{array}$ \\
\hline Issue Date & $2009-11$ \\
\hline Doc URL & http://hdl.handle.net/2115/43032 \\
\hline Rights & $\begin{array}{l}\text { This article has been accepted for publication in BJO following peer review. The definitive copyedited, ty peset version } \\
\text { Br J Ophthalmol 2009;93:1428-1430 is available online at : http://bjo.bmjjournal s.com/ }\end{array}$ \\
\hline Type & article (author version) \\
\hline Note & 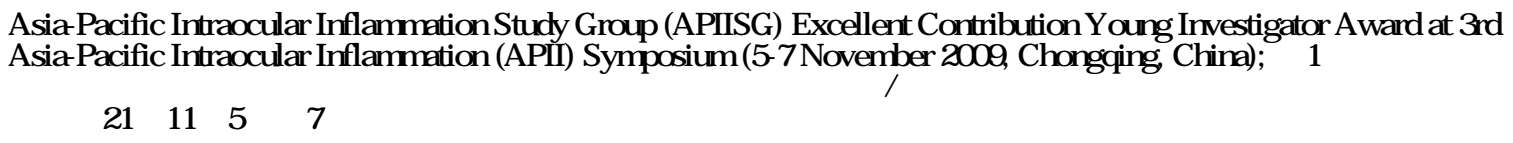 \\
\hline File Information & BJ093-11_p1428-1430.pdf \\
\hline
\end{tabular}

Instructions for use 


\section{Low prevalence of juvenile-onset Behcet's diease with uveitis in East/South Asian people}

Nobuyoshi KITAICHI ${ }^{1}$, Akiko MIYAZAKI ${ }^{1}$, Miles R STANFORD ${ }^{2}$, Daiju IWATA ${ }^{1}$, Hormoz CHAMS ${ }^{3}$, Shigeaki $\mathrm{OHNO}^{1,4}$

1. Department of Ophthalmology and Visual Sciences, Hokkaido University Graduate School of Medicine, Sapporo, Japan

2. King's College London, London, United Kingdom

3. Behçet's Research Center, Shariati Hospital, Teheran University for Medical Sciences, Teheran, Iran.

4. Department of Ocular Inflammation and Immunology, Hokkaido University Graduate School of Medicine, Sapporo, Japan

Correspondence to: Nobuyoshi Kitaichi MD, PhD

Department of Ophthalmology and Visual Sciences, Hokkaido University Graduate School of Medicine, Kita-15, Nishi-7, Kita-ku, Sapporo 060-8638, Japan

E-mail: nobukita@med.hokudai.ac.jp

Competing Interest: None declared

Licence for Publication

The Corresponding Author has the right to grant on behalf of all authors and does grant on behalf of all authors, an exclusive licence (or non exclusive for government employees) on a worldwide basis to the BMJ Publishing Group Ltd to permit this article (if accepted) to be published in BJO and any other BMJPGL products and sublicences such use and exploit all subsidiary rights, as set out in our licence (http://bjo.bmj.com/ifora/licence.pdf).

Key words: Iris; Choroid; Public health; Inflammation; Epidemiology 
Purpose: There is little information on the demographic and clinical characteristics of Behcet's disease in children in different parts of the world. We sought to provide this information through a questionnaire survey of specialist eye centres.

Methods: Descriptive questionnaires were collected from 25 eye centers in 14 countries. The questionnaire surveyed details of juvenile-onset Behcet's disease with uveitis. Ethnic groups, clinical features, treatments, and prognosis of pediatric-age Behcet's disease were examined on a world scale.

Results: The clinical data of 135 juvenile-onset and 1,227 adult-onset patients with uveitis were collected. The average age of disease diagnosis in the children was 11.7 years old. Of the ethnic groups identified: 54\% were from Middle East, 43\% from Europe, but only 2\% from East/South Asian countries. By contrast, $19.2 \%$ of adult patients were from East or South Asia. The frequency of genital ulcers in juvenile patients was $38.7 \%$, which was significantly lower than in adult cases $(53.5 \%$; $\mathrm{P}<0.01)$.

Conclusions: Behcet's disease with uveitis was less common in children than in adults in East/South Asia. Although the clinical features of the systemic disease were similar between children and adults, there was a lower frequency of genital ulceration in children. 


\section{Introduction}

Behçet's disease is a chronic multisystem disorder characterized by oral aphthous ulcers, genital ulcers, skin lesions, ocular lesions, gastrointestinal involvement, vascular lesions and neurological manifestations. The mean age of disease onset is $25-30$ years old, ${ }^{1}$ and initial presentation in children is uncommon. Details of the presentation and clinical characteristics of juvenile-onset Behçet disease have been limited to case reports or small case series. ${ }^{2-8}$

One of the manifestations of Behcet's disease is uveitis. In general, uveitis in childhood is uncommon with an incidence of 4-7/100,000 children per year. ${ }^{9-11}$ Unlike adults, juvenile idiopathic arthritis (JIA) is the most common identified cause of uveitis in children. ${ }^{12-14}$ Even in Turkey, one of the countries of highest prevalence of Behçet 's disease, JIA is the most common cause of uveitis in children, followed by idiopathic uveitis and pars planitis. ${ }^{15}$ Behçet's disease is one of the three most frequent diagnoses in patients with uveitis in Japan. ${ }^{16-18}$ Though the prevalence of Behçet's disease in the Japanese overall has been estimated to be $10-15 / 100,000,{ }^{19}$ juvenile-onset Behçet's disease is uncommon.

Accordingly, there is little information on the demography and clinical characteristics of Behcet's disease with ocular lesions in children. Against this backgound, we administered a descriptive questionnaire survey in a large-scale international collaborative study and compared the epidemiology, clinical phenotype and visual outcome between children and adults. A summary of the clinical features of the whole cohort has been recently reported. ${ }^{1}$

\section{Methods}

Descriptive questionnaires were sent to 132 ophthalmology centers by e-mail and airmail in 2005-2006. We encouraged participants as many subjects as possible to provide their clinical data to us. Also, we gave no detail of this survey of juvenile-onset Behcet's disease to avoid a source of bias about the recruitment of patients in their institutions. Responses were collected from 25 eye centers in 14 countries; Australia, Germany, Greece, India, Iran, Italy, Japan, Jordan, Morocco, Portugal, Turkey, Saudi Arabia, Tunisia, and the United Kingdom (UK). Races of the patients were also questioned. The inclusion criteria were patients who developed the disease at less than 16 years of age. The age of disease onset was 
recognized as the timing of meeting the classification criteria based on the estimation of the responding doctors. Statistical analysis was performed using the $\chi^{2}$ test or F-test. Values of $\mathrm{p}<0.01$ were considered statistically significant.

\section{Results}

The clinical data of 1,465 Behcet's patients were successfully collected. Of which 1,362 patients were reported the age of disease onet: 1,227 patients were considered adult-onset and 135 were juvenile-onet Behcet's disease. Boys accounted for $65.2 \%$ of the cohort of juvenile-onset patients (Table 1). HLA-B51 was detected in $68.6 \%$ of children and $61.6 \%$ of adult patients. The mean age of disease diagnosis in children was 11.7 years old, and the mean follow-up period was 13.5 years (Table 1 ). We were able to identify the ethnic groups of 127 children: $53.5 \%$ (68 cases) of them were from Middle Eastern countries, $43.3 \%$ (55 cases) of them from Europe, and only 2.4\% (3 cases) from East/South Asia (Fig. 1). One case was reported as Cuban of mixed race. Among adults, $19.2 \%$ of patients were from East/South Asia (Fig. 1). This difference in ethnicity was significantly different between adult-onset and juvenile-onset $(\mathrm{p}<0.004$, F-test $)$.

Among children, recurrent oral aphthous ulcers in $94.8 \%$, skin lesions in $67.4 \%$, and genital ulcers in $38.5 \%$ (Fig. 2). In adults, recurrent oral aphthous ulcers in $94.5 \%$, skin lesions in $70.0 \%$, and genital ulcers in 53.5\% (Fig. 2). The frequency of genital ulcers in juvenile patients was significantly lower than that of adult cases $\left(\mathrm{P}<10^{-8}, \chi^{2}\right.$ test). More than $90 \%$ (93.9\%) of juvenile patients had combined anterior and posterior segment intraocular inflammation (CAPSII/panuveitis) as adults. Most of the children suffered from bilateral recurrent CAPSII/panuveitis (Table 1). The percentage of eyes achieving a final visual acuity of $0.1(20 / 200)$ or better in the better eye was $92.6 \%$ of children (Table 1 ) and $86.3 \%$ among adults. Thus, $7.4 \%$ of children but $13.7 \%$ of adult patients were legally blind. A good visual prognosis $(\geq 20 / 200)$ was more frequent in children than in adult cases $\left(\mathrm{P}<0.033, \chi^{2}\right.$ test $)$.

The most frequently prescribed systemic therapy was corticosteroids (57 cases, $42.2 \%$ ), followed by cyclophosphamide ( 27 cases, $20.0 \%$ ), methotrexate ( 25 cases, $18.5 \%$ ), colchicine (18 cases, $13.3 \%$ ), azathioprine (12 cases, $8.9 \%$ ), cyclosporin (11 cases, $8.1 \%$ ), and interferon- $\alpha$ ( 2 cases, $1.5 \%$ ) (Table 2 ). 
Three quarters $(73.6 \%)$ of the patients received more than one drug.

\section{Discussion}

In the present study, we successfully performed an international collaborative survey of the phenotypes of children with Behcet's disease and uveitis. Although several diagnostic criteria are used to make the diagnosis of Behcet's disease in adults ${ }^{2021}$, there are none in children. ${ }^{22}$ This means that the epidemiology of pediatric Behçet's disease is difficult to evaluate because there is no general agreement about either the age of onset or the age of full diagnosis. Previous studies have shown that the proportion of patients in whom the onset of symptoms occurred under the age of 16 years varies. ${ }^{32324}$ A study of juvenile-onset Behçet's disease from France reported that the mean age of disease onset was 7.5 years old, but the mean age at which patients met the criteria for Behçet's disease was 11.6 years old. ${ }^{4}$ Since the mean age of disease diagnosis in our study was 11.7 years old (Table 1), our present results from an international study confirm these previous findings.

We showed that the visual prognosis was better in juvenile-onset patients than in adult-onset subjects. More than $20 \%$ of eyes of Behcet's patients of all ages become legally blind as reported recently. ${ }^{1}$

${ }^{25}$ In the present study, $93 \%$ of the juvenile patients had final visual acuity of $0.1(20 / 200)$ or better in their better eyes (Table 1), and visual prognosis was significantly better among children than adults. However, this statistical result may not always mean that the ocular involvement in children is milder than adults. The visual prognosis of patients from East/South Asia was poor compared with other countries in all age groups, as we reported. ${ }^{1}$ Also, the prevalence of East/South Asia was significantly lower than that of Middle East and European countries (Fig 1). Thus, only a few East/South Asian children, an unfavorable group, were included in the population of the present study. Furthermore, we did not have information on ocular co-morbidity (eg cataract, glaucoma, and/or macular degeneration) as a confounding factor, which might be expected to be more common in adults. We should take up one more point that cyclophosphamide was one of the most commonly used immunosuppressive agents shown in this study. Though it is true that this old drug is cheep and experienced well in many countries, it may not be recommended for children from its toxicity. 
The prevalence of oral and skin lesions were almost the same between children and adults, but quite different for genital ulcers. This is consistent with a previous study surveyed in Israel ${ }^{6}$. There is one possibility that the frequency of genital ulcer might be lower in patients before puberty. Genital ulcers were reported from $30.9 \%$ of the patients whose disease had started before 10 years old. Though the frequency was lower than that of older children (42.7\%), there was no statisitical significance. The reason why genital ulcers were less frequently seen in children than in adults is still unclear. It may be one of the features of younger patients with Behcet's disease.

Our study may contain some sources of bias as given previously ${ }^{1}$. (1) We did not ask which criteria were used to include patients in the study. The criteria for Behcet's disease accepted for selection included Japanese Committee's ${ }^{21}$, International Study Group's ${ }^{20}$, and O'Duffy's criteria. The use of different standardized criteria may lead to misclassification when comparing the frequencies of systemic features. However, since most of the colleagues were members of International Comittee of Behcet's disease as well as uveitis-specialists, we hope that the false positive rate of diagnosis may be quite low. Also, they had used the same one for inclusion of both juvenile and adult patients absolutely. (2) We also had only a limited response rate to the questionnaire from $25 / 132$ eye centers. Therefore the response may not have been representative of all countries and ethnic groups, it is the second possible source of bias. (3) There may have been reporting bias as the population was taken from tertiary referral centres and the cases may have been more severe, as the third source of bias. (4) Access to uveitis clinic may be another source of bias. Healthcare system is different in different countries. There may be some regional problems relevant to pediatric age group. However, when it comes to Japan, children can seek immediate medical attention as adults. It may be not enough reason of low prevalence of juvenile-onset Behcet's disease in East Asia. Japanese pediatricians previously surveyed Behcet's disease among children, however they were able to collect the medical data of only 31 cases from 1,290 hospitals throughout the country ${ }^{26}$. It may be true that the prevalence of the patients without ocuar symptoms is also low in Japan.

Although there were some sources of bias that may distort the results, the authors consider that a sufficient number of patients with a relatively uncommon type of disease were analyzed. The present results would provide an indication that the clinical features of juvenile-onset Behcet's disease with ocular 
lesions do differ from adult-onset disease in some respects.

In conclusion, the frequency of Behcet's disease showed racial differences in children. Only a few children suffered from Behçet's disease in contrast to the high prevalence in adults among East and South Asian people. The clinical features of Behcet's disease with uveitis were different between adult-onset and juvenile-onset patients: the prevalence of genital ulcers was less in children than in adults.

\section{Acknowledgement}

The authors are grateful to Drs Krause (Berlin, Germany), Becker, Mackensen (Heidelberg, Germany), Forrester, Kuffova (Aberdeen, UK), Dick (Bristol, UK), Markomichelakis, Palimeris (Athens, Greek), Ozyazgan, Tugal-Tutkun (Istanbul, Turkey), Akova (Ankara, Turkey), de Abreu, Proenca (Evola, Portugal), Benamour (Casablanca, Morocco), Tognon, Motterle (Padova, Italy), Khairallah (Monastir, Tunisia), Accorinti, Pezzi (Rome, Italy), Davatchi (Teheran, Iran), Madanat (Amman, Jordan), Tabbara, al Dalaan (Ryadh, Saudi Arabia), Biswas (Chennai, India), Gupta (Chandigarh, India), Hall (Melbourne, Australia), Namba (Sapporo, Japan), Okada, Kawaguchi, and Mochizuki (Tokyo, Japan) for providing observation data. This study was supported by grants from the Ministry of Education, Culture, Sports, Science and Technology

(MEXT) Japan, and the Ministry of Health, Labor and Welfare Japan. 


\section{Figure legends}

Figure 1. Ethnic groups of patients with Behcet's disease

Middle Eastern, Caucasian, and East/South Asian people were 3 major ethnic groups of Behcet's disease among adults, however, only a few East/South Asian patients suffered from the disease in childhood $(\mathrm{p}<0.01)$.

Figure 2. Major symptoms of Behcet disease

Frequency of genital ulcers was significantly lower in children than in adults $(\mathrm{p}<0.01)$.

Table 1. Summary of juvenile-onset Behcet's disease in eye centers $(\mathrm{N}=135)$

$\begin{array}{ll}\text { Boys } & 65.5 \% \\ \text { HLA-B51 } & 68.6 \%\end{array}$

Age of disease onset

11.7 years old

Mean follow-up period

13.5 years

CAPSII*/panuveitis

$93.9 \%$

Bilaterality

$83.6 \%$

Recurrence of ocular inflammation

$96.3 \%$

Poor visual prognosis $(<20 / 200$, better eyes $)$

$7.4 \%$

*CAPSII: combined anterior and posterior segment intraocular inflammation

Table 2. Initial sysytemic therapies for children*

$\begin{array}{lc}\text { Corticosteroids } & 42.2 \% \\ \text { Cyclophosphamide } & 20.0 \% \\ \text { Methotrexate } & 18.5 \% \\ \text { Colchicine } & 13.3 \% \\ \text { Azathioprine } & 8.9 \% \\ \text { Cyclosporin } & 8.1 \% \\ \text { Interferon-alpha } & 1.5 \%\end{array}$

*Three quarters of patients received two or more drugs as their initial therapies 


\section{References}

1. Kitaichi N, Miyazaki A, Iwata D, et al. Ocular features of Behcet's disease: an international collaborative study. Br J Ophthalmol 2007;91:1579-82.

2. Jog S, Patole S, Koh G, et al. Unusual presentation of neonatal Behcets disease. Am J Perinatol 2001;18:287-92.

3. Kim DK, Chang SN, Bang D, et al. Clinical analysis of 40 cases of childhood-onset Behcet's disease. Pediatr Dermatol 1994;11:95-101.

4. Kone-Paut I, Gorchakoff-Molinas A, Weschler B, et al. Paediatric Behcet's disease in France. Ann Rheum Dis 2002;61:655-6.

5. Kone-Paut I, Yurdakul S, Bahabri SA, et al. Clinical features of Behcet's disease in children: an international collaborative study of 86 cases. J Pediatr 1998;132:721-5.

6. Krause I, Uziel Y, Guedj D, et al. Childhood Behcet's disease: clinical features and comparison with adult-onset disease. Rheumatology (Oxford) 1999;38:457-62.

7. Yamazaki S, Koyano T. A case of pediatric Behcet's disease with intestinal involvement. J Dermatol 1999;26:160-3.

8. Yazici H, Tuzun Y, Pazarli H, et al. Influence of age of onset and patient's sex on the prevalence and severity of manifestations of Behcet's syndrome. Ann Rheum Dis 1984;43:783-9.

9. Edelsten C, Reddy MA, Stanford MR, et al. Visual loss associated with pediatric uveitis in english primary and referral centers. Am J Ophthalmol 2003;135:676-80.

10. Gritz DC, Wong IG. Incidence and prevalence of uveitis in Northern California; the Northern California Epidemiology of Uveitis Study. Ophthalmology 2004;111:491-500; discussion 00.

11. Paivonsalo-Hietanen T, Tuominen J, Saari KM. Uveitis in children: population-based study in Finland. Acta Ophthalmol Scand 2000;78:84-8.

12. Cunningham ET, Jr. Uveitis in children. Ocul Immunol Inflamm 2000;8:251-61.

13. Kadayifcilar S, Eldem B, Tumer B. Uveitis in childhood. J Pediatr Ophthalmol Strabismus 2003;40:335-40.

14. Stoffel PB, Sauvain MJ, von Vigier RO, et al. Non-infectious causes of uveitis in 70 Swiss children. Acta Paediatr 2000;89:955-8.

15. Tugal-Tutkun I, Havrlikova K, Power WJ, et al. Changing patterns in uveitis of childhood. Ophthalmology 1996;103:375-83.

16. Akiyama K, Numaga J, Yoshida A, et al. Statistical analysis of endogenous uveitis at Tokyo University Hospital (1998-2000). Jpn J Ophthalmol 2006;50:69-71.

17. Goto H, Mochizuki M, Yamaki K, et al. Epidemiological survey of intraocular inflammation in Japan. Jpn J Ophthalmol 2007;51:41-4.

18. Kitamei H, Kitaichi N, Namba K, et al. Clinical features of intraocular inflammation in Hokkaido, Japan. Acta Ophthalmol:In press.

19. Kitaichi N, Ohno S. [Behcet's disease]. Nippon Rinsho 2005;63 Suppl 5:376-80.

20. ISGBD. Criteria for diagnosis of Behcet's disease. International Study Group for Behcet's Disease. Lancet 1990;335(8697):1078-80.

21. Mizushima Y. Recent research into Behcet's disease in Japan. Int J Tissue React 1988;10:59-65.

22. Kitaichi N, Ohno S. Behcet disease in children. Int Ophthalmol Clin 2008;48:87-91.

23. Sarica R, Azizlerli G, Kose A, et al. Juvenile Behcet's disease among 1784 Turkish Behcet's patients. Int $J$ Dermatol 1996;35:109-11.

24. Treudler R, Orfanos CE, Zouboulis CC. Twenty-eight cases of juvenile-onset Adamantiades-Behcet disease in Germany. Dermatology 1999;199:15-9.

25. Yang P, Fang W, Meng Q, et al. Clinical features of Chinese patients with Behcet's disease. Ophthalmology 2008;115:312-18.

26. Fujikawa S, Suemitsu T. Behcet disease in children: A nationwide retrospective survey in Japan. Acta Paediatrica Japonica 1997;39:285-189. 


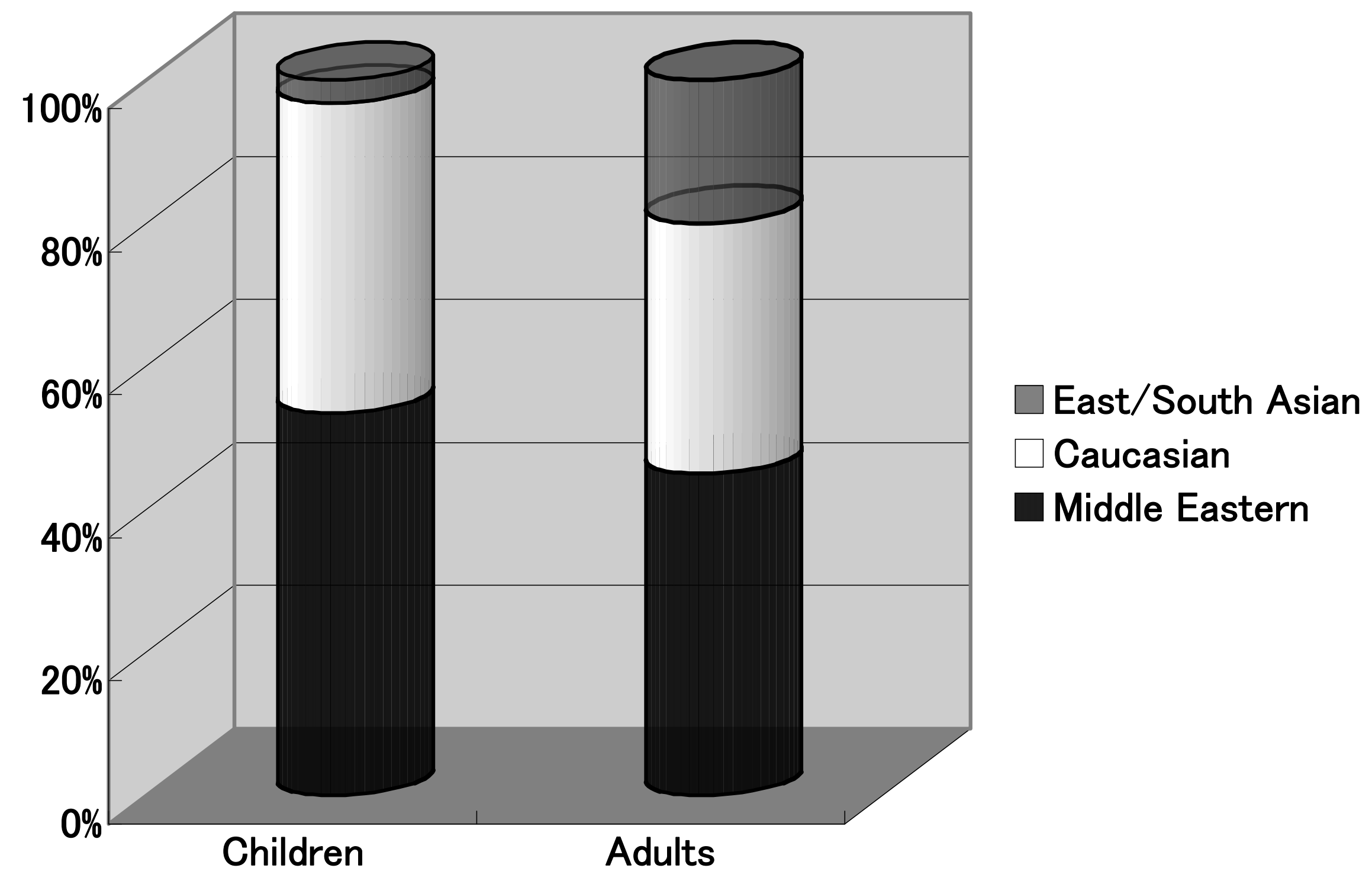




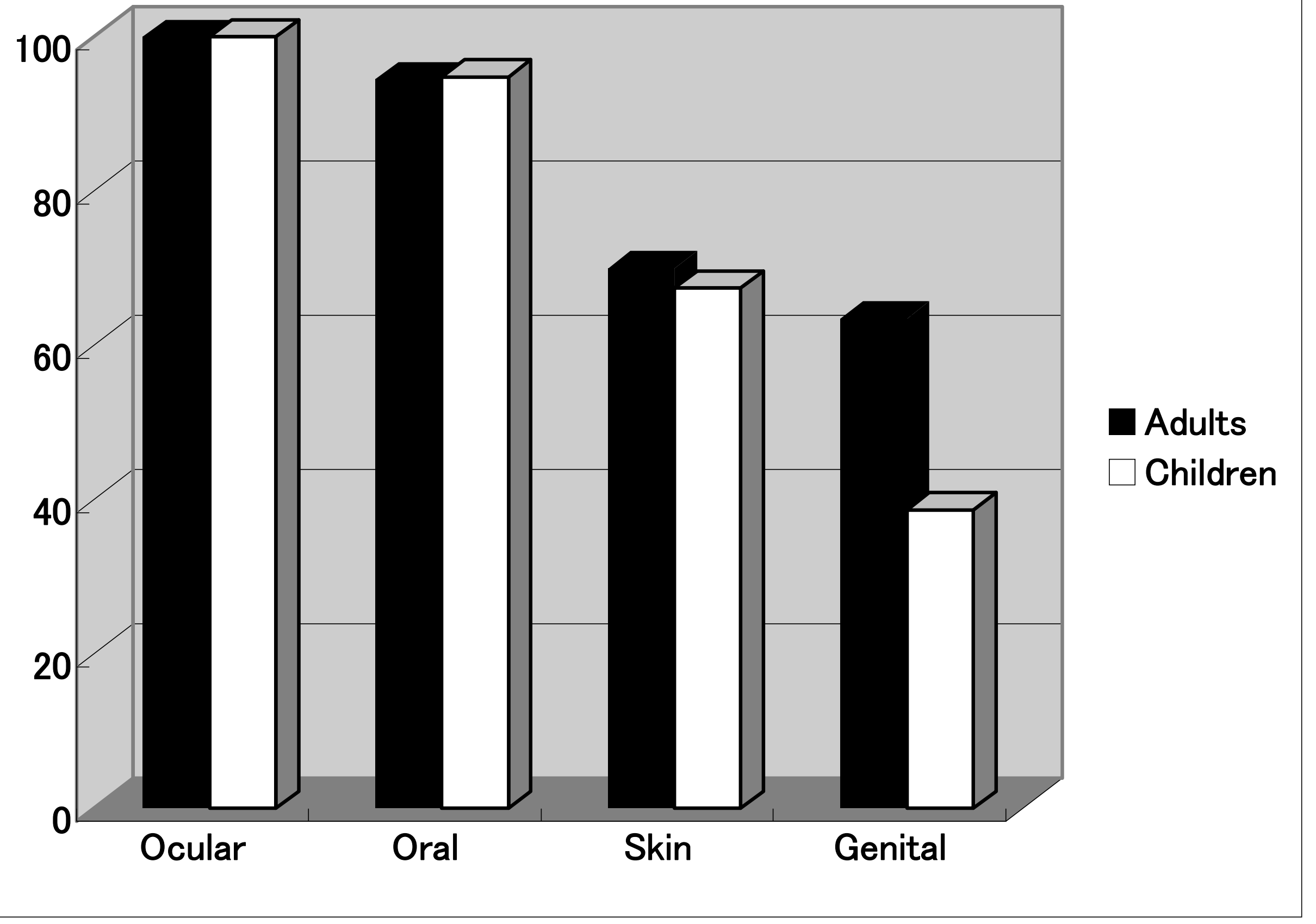

